\title{
AC 2008-1141: IMPACTS OF AN ENGINEERING RESEARCH EXPERIENCE FOR TEACHERS ON CLASSROOM INTEGRATION OF STEM CONCEPTS IN GRADE 6-12 SCIENCE
}

\section{Brant Miller, University Of Minnesota}

Brant Miller is a doctoral student in Science Education at the University of Minnesota - Twin Cities. He received his B.S and M.S degrees from Black Hills State University in the field of Education. Before pursuing his doctoral work, Brant was a middle school science teacher for six years. His research interests include the infusion of engineering content into the K-12 curricular framework and professional development for K-12 STEM teachers.

\section{Tamara Moore, University Of Minnesota}

Tamara J. Moore is a Assistant Professor of Mathematics and Engineering Education in the Department of Curriculum and Instruction at the University of Minnesota. She received her Ph.D. in Engineering Education, her M.S.Ed. in Mathematics Education and her B.S. in Mathematics from Purdue University. Tamara taught high school mathematics for seven years prior to pursuing her doctorate. Her research interests include curriculum development, the learning of complex problem-solving in mathematics and engineering, teamwork, and integration of engineering into the K-12 STEM classroom. 


\title{
Impacts of an Engineering Research Experience for Teachers on Classroom Integration of STEM Concepts in Grade 6-12 Science
}

\begin{abstract}
The main objective of the South Dakota School of Mines and Technology (SDSM\&T) Research Experience for Teachers (RET) Site: "Inspiring Educators in Rural America through Research" is to provide an authentic research experience to practicing middle and high school science, math, and technology teachers. It is our goal that from this research experience the teachers can take back to their respective classrooms knowledge, and content which they will readily share with their students. After completing three summer sessions and subsequent workshops of our RET program, we feel very confident in endorsing this model of professional development as effective and noteworthy. This study looks at the evaluation data from the 2007 cohort of teachers in the SDSM\&T RET program and at one teacher in depth. This paper will answer the research question: In what ways does the experience in the SDSM\&T RET program effect teacher perception of change in teaching practices? To answer this question: a longitudinal case study was conducted specifically looking at one teacher who participated during the 2007 RET program.
\end{abstract}

\section{Introduction}

A great amount of effort has gone into improving the science education of our young people ${ }^{1,2}$. From curriculum reform to parent programs, many avenues have been explored to find the answers to best practices and effectiveness for all students no matter what the student is bringing to the metaphoric education table. The complexity and interrelatedness of the issues are overwhelming. For the purposes of this paper, the professional development of K-12 science teachers in a Research Experiences for Teachers (RET) Program at South Dakota School of Mines and Technology (SDSM\&T) will be the focus. The RET model is a promising approach to

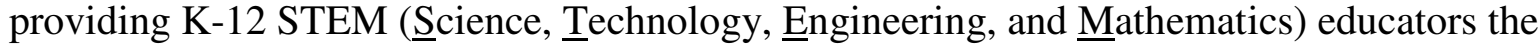
professional development experiences needed to garner authentic student achievement. The main objective of the SDSM\&T RET program is to provide an authentic research experience to practicing middle and high school science, math, and technology teachers. It is our goal that from this research experience the teachers can take back to their respective classroom knowledge and content which they will readily share with their students. After completing three summer sessions and subsequent workshops of our RET program, we endorse this model of professional development as effective and noteworthy. This study looks at the evaluation data from the 2007 cohort of teachers in the SDSM\&T RET program and at one teacher in depth. This paper will answer the research question: In what ways does the experience in the SDSM\&T RET program effect teacher perception of change in teaching practices? To answer this question: a longitudinal case study was conducted specifically looking at one teacher who participated during the 2007 RET program. 


\section{The Need for Professional Development}

A precept of professional development can be stated "that improving teacher preparedness will lead to higher-quality instruction and, in turn, increased student learning"3. Unfortunately, professional development has historically been the bane of the teaching profession. From one day workshops with advice and tips that veteran teachers have heard countless times; to lack of responsibility for the absence of a professional development infrastructure that would promote consistency, coherence, and a much needed curriculum; the picture of professional development in the United States has been bleak ${ }^{4}$.

Our nation is experiencing an emphasis on the development of scientific literacy for K-12 students that has not been seen since the United States found itself behind in the Space Race following the launch of Sputnik by the Russians in the late 1950's '. It is becoming evident to all observers that the competitiveness of other nations is challenging the dominance of the United States in STEM fields, which are critical to longitudinal solvency. The federal government is advised by special reports and advisory councils on the current state of affairs concerning STEM fields ${ }^{6,7}$. The immediate action is to get to the root of the problem; in this case, the dwindling pipeline of future STEM professionals, and why the pipeline is dwindling ${ }^{7}$. This situation has consequently led to a critical look at the overall education system within the United States and initiatives that attempt to curb the downward spiral noted previously.

A systemic effort to enhance science teaching and learning comes in the form of seminal publications that are meant to guide future decisions in K-12 science education. The two publications referred to are the National Science Education Standards ${ }^{8}$ and Science for All Americans ${ }^{9}$. Both publications promote efforts that are fundamentally different from the traditional delivery of science education. For example, teachers are expected to build upon students' prior knowledge while at the same time having inquiry as an underlying concept within all scientific discourse. As part of the new paradigms of science education, recommendations for teacher professional development is also explored ${ }^{8}$. The main precept of Science for All Americans as the title implies is that all students should have the opportunity to become scientifically literate. Hence, teachers are central to the success of this charge and therefore need to have the support in the form of accurate and high quality professional development to reach these ends ${ }^{9}$.

\section{Research Experiences for Teachers Program as Teacher Professional Development}

The Research Experience for Teachers program was established in 2001 by the National Science Foundation (NSF) as an outgrowth of the popular and successful NSF Research Experience for Undergraduates (REU) program ${ }^{10}$. The motivation for the NSF funding such a program is "to bring knowledge of engineering and technological innovations to the pre-college classroom" Rather than attempt to fund programs that directly impact students, the NSF is supporting programs that impact teachers through their participation in authentic research experiences. By impacting teachers, the NSF's original investment goes much further considering the number of students each participating teacher will interact with each school year. 
To provide this impact upon teachers, the RET model is set up so that each participating teacher spends a minimum of six weeks within an engineering research laboratory. As could be expected, each institution has a slightly different approach to RET program administration; therefore, the tasks RET participants engage in are not homogenous. For example, one university may not have RET participants directly collect data, instead having them observe researchers and the tasks they conduct while spending a majority of their time developing curriculum from these observations. Another university may have a completely different philosophy for their RET participants, such as the expectation that they will be valued contributors to the research enterprise, expected to become familiar with the research questions and the accompanying literature, develop procedures, conduct experiments, and collect data. The focus of the six or more weeks in the lab is research, however this takes shape. Beyond the research there are often a variety of supplemental activities meant to enrich the research experience as well as provide support and strategies for transferring research content back to the classrooms of the respective teachers. Common supplemental activities include: field trips to other labs, research team meetings, brown bag lunch discussions, poster sessions, and social events to build community. Follow-up activities are also an integral component of RET programs. These activities can consist of school year workshops, ongoing faculty collaborations, and support infrastructures.

The RET model of professional development has great appeal to, and impact on, STEM teachers for a variety of reasons including content knowledge, STEM community immersion, doing inquiry, and general scientific confidence to name just a few ${ }^{11-23}$. In an effort to touch upon the overarching impacts of the RET model of professional development, three categories will be explored; the three categories are: content, nature of science, and STEM community interactions.

Beginning with a discussion of content in a broad definition of the word; what gives the RET model of professional development such great appeal is that it allows pre-service and in-service STEM teachers to actively contribute to the greater body of knowledge in their fields. Students often look upon teachers as a storehouse of scientific knowledge, steeped in the finer points of their respective content area. The truth is many science teachers have never had an opportunity to conduct scientific research. The RET model allows for a greater sense of validity for those who teach STEM content ${ }^{24}$. The subsequent knowledge gained from such experiences is significant for teachers who are lacking the content background as well as for those who may have the content background but may not be well versed in the latest research developments in a specific field of science or engineering.

One of the underlying themes within the National Science Education Standards ${ }^{8}$ is the concept of inquiry, and teachers' abilities to create authentic, contextual, inquiry activities for students. The RET model provides teachers with an experience that can be drawn upon when guiding students. Closely related to the concept of inquiry is the nature of science which provides a lens for teachers and students when solving problems or building knowledge.

A final point to make about the impact the RET model of professional development has on teachers is that of being involved with the leading edge of scientific and engineering research. As teachers interact with the highly motivated, high-energy atmosphere that is found in university research laboratories, they become rejuvenated. The rejuvenation they feel for getting back into the classroom the following fall term is, in part, a result of being a working part of the science 
and engineering communities which are building a knowledge that has never been done before. It is because of this integration with the practicing science community that teachers feel their knowledge of science has greater validity, and subsequently, teachers feel excitement for getting back to their classroom to share their experience in the role of practicing scientist with students.

\section{Research Experiences for Teachers and the Impact on Students}

Student impact from the RET model of professional development is of great interest to the NSF and to those responsible for administering such programs. It is easy enough to put highly motivated, effective teachers into an engineering research lab, an act that will have numerous positive impacts, and receive incredibly positive feedback. It is quite another task to then gauge how effective the professional development was based on student factors, such as academic achievement, science/engineering interest, and/or future academic and career directions of students. The problem, as stated by Borko ${ }^{25}$ is that research is only beginning to understand "the impact of teacher change on student outcomes."

Research conducted directly on student impact from RET style programs has shown to be a difficult task. Virtually all of the assessments on how RET model programs impact students have been through teacher participant reports instead of observing student outcomes directly ${ }^{10,24}$. Although teacher participant reports may show seemingly significant gains in student awareness, attitudes, and interest per classroom, this style of research lacks the necessary rigor to begin claiming a correlation between the RET model of professional development and gains in student achievement and STEM knowledge.

Only recently has longitudinal data begun to emerge, quantifying student impact. During the proceedings of the conference on teacher research experiences, April 24-27, 2005, Dubner and Storm shared preliminary results of their study assessing student impact over a period of ten years. From this study a notable results was the finding that $12 \%$ more students passed the regents science exam in the state of New York after having been under the tutelage of a teacher who had participated in a RET model program versus comparison groups ${ }^{24}$.

\section{Overview of SDSM\&T RET Program}

The main objective of the South Dakota School of Mines and Technology (SDSM\&T) Research Experience for Teachers (RET) Site: "Inspiring Educators in Rural America through Research" is to provide an authentic research experience to practicing middle and high school science, math, and technology teachers. As an outcome of the research experience, the teachers take back to their classroom newly acquired experiences, knowledge, and demonstrations which they will readily share with their students. The objectives of the SDSM\&T RET Site are:

1. to provide ten (10) sixth through twelfth grade teachers (RET Research Assistants) the opportunity to work side-by-side with undergraduate students, graduate students, and faculty mentors in the exciting enterprise of research;

2. to provide RET Research Assistants an experience from which they can draw ideas and develop skills that they can then transfer to their own classrooms;

3. to provide an environment to develop methods to transfer the excitement of research to 612 th grade students; and 
4. to provide an opportunity to form lasting professional relationships and collaborations between teachers and between teachers and mentors; e.g., course material development on-campus field trips, summer research and visiting scientist and engineers to middle and high schools.

The primary vehicle to attain our goals is the "on-campus" research component. During this five week intensive, on-campus immersion into research the RET Research Assistants (RAs) are expected to be an integral part of the research being undertaken by faculty and select graduate and undergraduate students assigned to their particular project. To prepare RET RAs for this relatively short research window; RET RAs take part in an Advanced Preparation (AP) component of the program prior to coming on to campus. During the AP experience the RET RAs are expected to become familiar with the literature provided by their faculty mentor and to ask questions via email or face-to-face as logistics allow to begin the professional dialogue on the topic. When RET RAs arrive on campus a short amount of time is given to orientation activities and introductions, and then they begin work on the research tasks to be explored. Besides the research, there are a number of activities scheduled both during the on-campus experience and after. These are designed to enrich the core research experience. A brief synopsis of these activities is as follows:

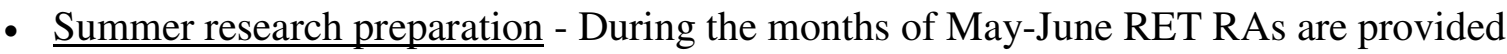
with research background; faculty mentor needs are assessed; the ability and understanding of RET RAs is assessed; and on campus visits are arranged where applicable.

- SDSM\&T RET Program Orientation - RET RAs become familiar with the SDSM\&T campus including: library facilities; computing facilities; relevant research instruments and facilities. Faculty mentors briefly participate by introducing themselves to the overall group as well as providing a brief synopsis of RET RA research goals and objectives. Paperwork is completed for graduate credit and an entrance survey is administered. All of the aforementioned gives RET RAs the tools to successfully begin their on-campus experience.

- Formal and Informal Meetings - Research presentations are given by RET RAs to share experiences; open-ended discussions commence on relevant topics. RET RA's have expressed perceived value in learning about the research being done by their colleagues.

- Brainstorming Sessions - Identify methods to transfer freshly gained knowledge into 6-12 classrooms. Strategies and techniques are discussed from two texts, Understanding by Design by G. Wiggins and J. McTighe ${ }^{26}$ and Concept-Based Curriculum and Instruction by H. L. Erickson ${ }^{27}$.

- Campus and Community lab tours and demonstrations - Each week RET RAs have the opportunity to visit lab facilities to gain a greater appreciation of the types and levels of research taking place on campus and beyond. Often times RET RAs' eyes are opened to the impressive depth and breadth of research occurring in such close proximity their K-12 facilities.

- Brown Bag Lunch Discussion Series - Faculty Mentors are asked to consider being a featured speaker during our weekly gatherings. These lunches provide faculty mentors with an opportunity to discuss research topics and backgrounds in an informal setting. The intent of these lunches is to build camaraderie. 
- Final Presentations/Research Symposium - A Poster session is organized in conjunction with REU programs on campus. This provides RET RAs the opportunity to experience a reality of research reporting at a professional conference. The poster then becomes a valuable teaching tool for the following school year along with being a keepsake to commemorate their summer activities.

- Exit Proceedings - All required materials are collected. A post program survey is administered. Closure is brought to the five-week on-campus experience.

- Workshops - The workshops during the school year following the on-campus research experience serve many purposes. In short, the Fall Workshop serves to be a final preparation of materials and logistics prior to delivery of Instructional Unit (IU). The Spring Workshop looks at outcomes and results of the IU and has participants discuss ways in which the IU can be adjusted to be more effective in future deliveries. At workshops, participants are asked to complete selected writing prompts to aid the program directors with RET program assessment.

The SDSM\&T RET program is situated in Rapid City, the second largest city in South Dakota a state with a total population just below 800,000. Due to the rural nature of the host state and institution, the RET program faced unique challenges. For example, the small size of SDSM\&T allowed for a RET program that spanned a variety of departments throughout campus, with no one department having a research agenda robust enough to serve all ten teachers. Distance was another factor. Traditionally about half of the teachers involved in the program had residences beyond a commutable distance; therefore housing accommodations were secured on-campus. Promotion of the program also proved challenging at times due to the remoteness of many of the schools within South Dakota. It is not uncommon for a science or mathematics teacher to be responsible for teaching all of the courses within their particular discipline, grades 9-12.

\section{Methodology}

\section{Case Study}

An embedded, single-case Naturalistic case study method was used to determine the impact the RET program had on our participant ${ }^{28-30}$. The purpose of the case study research was to explore in depth the teacher's perception of her changes in teaching practices as a result of participation in the SDSM\&T RET program. Multiple sources of data include: (a) participant's application to the RET program which includes a short narrative discussing the participants interest in applying for the program; (b) a pre-program survey; (c) a post-program exit survey; (d) an instructional unit written by the participant during participation in the RET program; (e) a post-program survey given two months after the program; (f) an in-depth interview six-months after the program; and (g) a classroom observation completed by our research team six-months after the completion of the RET program. In an effort to establish rigor and credibility for the study, parameters such as triangulation of data source and multiple researcher analysis was employed as described by Darke, et $\mathrm{al}^{29}$.

\section{Data Collected}

A variety of artifacts from the SDSM\&T RET program were collected in an effort to tease out 
the perceptions of change the participating teacher experienced. Each artifact will be discussed keeping a consistent chronological progression from first interactions with the teacher participant to the layers of follow-up data after the on-campus research experience.

Beginning with the participant application, the process involves demographic information collection along with letters of recommendation and a curriculum vita. For this study, particular attention was given to the written essay from the prompt: "please provide a short narrative (no more than one page) discussing your interest in the program highlighting the self motivation you have displayed in past endeavors". From this essay a sense of the participants past professional development efforts could be gleaned as well as how those efforts have translated to the classroom.

The pre- and post-program surveys collected provided a variety of data from teaching strategies to program impressions. The pre-program survey dealt primarily with teaching beliefs and style issues that could provide baseline data as to the types of instructional approaches and philosophies the participating teachers were bringing with them to the research program. The post-program survey dealt much more specifically with program impressions and therefore was asking for short answer or essay style responses versus the Likert or quantitative responses to the pre-program survey.

As part of the graduate course work ancillary to the research experience, participants were asked to make predictions. Many of the efforts outside of the core charge of research revolved around the transferability piece, which took on the form of an instructional unit. This instructional unit was to capture the essence of the participants experience within a research facility. To gauge participant sentiment, reflection was requested according to two writing prompts. The first, "make an in-depth prediction of success for the proposed instructional unit," gets participants thinking about some of the unplanned difficulties that may arise during the course of the instructional unit. The second had participants "complete a 1-2 page paper reflecting on the transferability of research concepts experienced." From these writing samples, the researchers hoped for prediction and reflection looking ahead at those factors that would dictate the success or failure of the developed instructional unit; and to define those factors which are intrinsically valued by participants. These values will be highlighted within their practice as evidenced by what is ultimately transferred from research lab to classroom.

After the on-campus research experience, participants went back to daily routines of teaching and interacting with students. To capture the subtle layers of impact to perception, iterative writing prompts were given approximately three months and six months after the experience. The motivation for this approach was two fold. First, by having participants reflect on similar topics over time, a sense of permanence can be gathered if similar themes appear during each reflection. Second, by giving time for reflection and normalcy, participants may share previously unarticulated outcomes of the RET model for professional development. The questions for the three month writing exercise were:

1) Explain the overall research project and goals that you participated in this past summer;

2) Discuss your contribution to this research project during your time on campus;

3) Discuss major findings from the above contribution; 
4) Describe the research and teaching skills you have or will be taking with you form this RET program; and

5) Isolating the RET programs impact on your professional practice. How do you perceive your RET experience furthering the development of future scientists, engineers and technicians or contributing to producing a scientifically literate population? Please provide ideas on how to gauge this impact.

The six-month interview highlighted questions relating to teaching impact at the micro (day to day) and macro (big picture or longitudinal) level, as well as perceptions of engineering and research. The classroom observation utilized the Oregon Teacher Observation Protocol $(\mathrm{OTOP})^{31}$ classroom observation tool. For the purposes of this case study, this artifact will be saved for later analysis.

\section{Data Analysis}

From the aforementioned artifacts the researchers looked at those pieces of data which would be most fruitful in addressing the research question: In what ways does the experience in the SDSM\&T RET program effect teacher perception of change in teaching practice? With this in mind, focus was given to the artifacts that allowed for greater expression in the form of short answer or essay type responses. The artifacts in question are: the application essay, post-program survey and reflective essays as part of the offered graduate courses, three month written response, and six month interview. From these artifacts, two researchers read through the artifacts in their entirety and developed a set of coding schemes independently. The codes revolved around those items that illustrated a positive shift in perception that would correlate to desired outcomes with students. After independent reading and coding the two researchers compared coding systems and built a master set of codes that was a negotiated melding of independent codes that presented greater clarity over the original independent coding schemes. The final set of codes used for the qualitative analysis is as follows:

- Students as Scientists/Engineers (SAS) - expression of desire for students to know science is possible. For students to take their current understanding to a new depth.

- Facility Impression (FI) - expressions of amazement, excitement, and impression over facilities and instrumentation found within SDSM\&T and the greater Black Hills region.

- Ownership (O) - expression of the research being a topic of expertise. A tone of authority and investment.

- Understanding Research (UR) - a new or different understanding of the enterprise of research, i.e. logistics, reality, lack of glamour, etc.

- Collaboration (C) - expression of future desires or plans of working with or utilizing university or research personnel.

- Content Increase (CI) - expressions of increased content knowledge for the betterment of lesson delivery.

- Procedural to Conceptual understanding (P-C) - capturing the shift from strictly following procedures to personal synthesis. Extending explanations for meaningful output.

- Engineering Perception (EP) - any expression of a shift in perception of engineering or engineers.

These codes were used to look at the artifacts in chronological order from the spring application, to summer writing samples at the conclusion of the program, to the three and six month artifacts. The researchers were looking for trends and shifts in perception over time through the use of 
coding analysis from the writing and interview artifacts.

\section{Results}

\section{SDSM\&T Program Effectiveness Overview}

Overall the SDSM\&T RET program has enjoyed great success as expressed by past participants. There are five core outcomes that resurface year after year when participants are asked to qualify the value of the program. Each of the five core outcomes overlap with one another yet present a unique perspective. Beginning with first hand knowledge of science and engineering; teachers who participate in RET programs generally do not have an extensive research background. By giving teachers the opportunity to be a contributing member of the research enterprise they proudly speak of the first hand knowledge they now posses. This first hand knowledge when expressed brings with it validity in the eyes of students.

Validity being the second core outcome, the impact of this outcome should not be taken lightly. When a teacher extends the effort to sacrifice a significant portion of their summer to engage in research it shows students that they are serious about their profession and want to extend the most accurate definitions on content possible, not to mention the expression of actually enjoying the subject they teach. It would seem that with the greater sense of validity students extend to the teacher; many of the roadblocks to learning have been broken down, i.e. apathy and relevance.

A third core outcome is an increase in content knowledge. When a teacher leaves the SDSM\&T RET program they can be assured of having just experienced and immersion into content unlike previous experiences. Albeit narrow in focus because of the fundamental nature of the research, the content knowledge increase has ramifications that transcend into fundamentals of research and the scientific method. Often time's participants will talk about the unexpected references to the research experience that were completely unrelated to the high level of fundamental research.

The increase in content knowledge can be related to an increase in understanding the enterprise of research, our fourth core outcome. A curricular charge found throughout state and national standards would be that of preparing a scientifically literate citizenry. At the core of this charge is a working understanding of the scientific method and it's fluid nature. By giving teachers first hand experience of guided inquiry, they are much more likely to have the ability to teach and explain this fundamental concept from a variety of angles, increasing the likelihood of meeting the needs of all learners.

A final core outcome would be the idea of recharging. For a teacher to be stimulated academically with a group of peers is valuable considering the taxing nature of teaching in a $\mathrm{K}$ 12 classroom setting. The excitement generated by a greater ability to teach the subject in which they are employed is exciting to many teachers. This along with coming alongside the cutting edge of research and the sense that what they are doing has never been done before and will add to the foundation of human knowledge is understandingly cause for an excitement that equates to a rejuvenated outlook on what some teachers have been doing for 20 plus years. The core outcomes expressed do have ramifications for students. Unfortunately the quantifying of student impact requires a longitudinal research model, which is outside of the scope of the current study. 


\section{Example of a Research Experience}

Our case study participant, Betty (pseudonym), participated in a research project in Bioengineering as part of the RET program. The department is of small size with only two professors within the specific research vein of bioengineering. This research is done under the auspices of the larger department of Chemical and Biological Engineering (CBE). The two faculty have aggressively sought grant dollars and opportunities which developed into preliminary research in the National Science Foundations newly awarded Deep Underground Science and Engineering Laboratory (DUSEL) at the decommissioned Homestake gold mine in Lead, SD.

The specific research project was titled "Biodegradation of cellulose using thermophiles isolated from the deep underground mine, Homestake Gold Mine in South Dakota". The goals of the project were twofold. First, specific to DUSEL, because of the conditions created in a deep underground laboratory setting, unique organisms that have not been studied before are thought to hold solutions to man-made problems above ground because of the high temperature in which these organisms survive and thrive. By using bacteria with the aforementioned properties from the DUSEL at Homestake, it is hoped that these organisms can be engineered to be applied to landfills to increase landfill decomposition and to discover the effective enzymes present to use for ethanol production. The second goal for Betty's summer research experience was to identify microorganisms in atypical soil samples using 16S rDNA molecular marker gene. By researching various soil samples from areas with high metal concentrations, it is possible to find which bacteria have the capabilities of degrading the metals. These bacteria can then be used to "recover" areas that have been affected by runoff from mines.

From the research premises, Betty contributed in the following ways beginning with the former. Bacteria from the DUSEL (specifically G12a and R11) that had already been identified were grown in cultures for 7-10 days. Daily protein estimations were done to record the bacterial growth under optimal conditions. From this point, new cultures were started to compare the bacterial growth on different types of cellulose. Daily readings were done to estimate bacterial growth. The Kim wipes (delicate task wiper similar to tissue paper) showed the greatest bacterial growth in both samples. For the latter contribution, starting with the soil sample: DNA was extracted and purified. A Polymerase Chain Reaction (PCR) machine was used to amplify the $16 \mathrm{~S}$ rDNA gene, which is used in bacteria identification. From this point the PCR product was purified, then legated (attaching an antibiotic resistant gene to the plasmid). The resulting plasmids were placed into "competent" E. coli bacteria and grown on a plate. The cultures that successfully underwent the process grew white on the plate. The plasmids were extracted from those colonies and sent of for DNA sequencing. The outcomes from the two research objectives secured by Betty were as follows continuing with the same order as previously. The $\mathrm{G} 13\left(37^{\circ} \mathrm{C}\right)$ and R11 $\left(60^{\circ} \mathrm{C}\right)$ bacteria estimated growth in the Kim wipes was significantly greater than the growth in the catalog paper, cotton, cellulose and CMC samples. Outcomes for the partner project were also notable in that there were multiple new species of bacteria identified through the BLAST database. 


\section{Betty's Experience}

Betty came into the SDSM\&T RET program with six years teaching experience in middle school science, primarily Life science. Betty received a B.S. in Biology and Secondary Education and a M.S. in Curriculum and Instruction to round out her formal training as a scientist and an educator. It must be noted that at no point during her formal academic training did Betty have the opportunity to conduct or participate in authentic science or engineering research. Over her teaching career, Betty has proven to be a very active participant in professional development opportunities and curricular development activities within her school district and also within the state of South Dakota. She had also completed the National Board Certification application process prior to RET participation. Of the eight codes, two will be highlighted for their revealing nature in response to the research question, UR and C. The code, SAS, will lead off the discussion because it frames Betty's philosophy of the type of experience her students should be having in her class and the results of that experience. The remaining codes (FI, O, CI, P-C, and EP) each display flashes of merit. For the purposes of this paper the results of these codes will remain in their current form, unexplored. Further analysis needs to occur within CI and P-C to tease out subtleness therein. FI, O and EP are straightforward in nature but don't necessarily illuminate research question conclusions.

\section{Students as Scientists}

Upon arriving on campus to participate in the RET program, it was clear that Betty had some core beliefs about the outcomes she valued as a science teacher. When analyzing the coded artifacts, the SAS code was a consistent theme within Betty's writing. Beginning with her application artifact, Betty expressed that she was "eager to learn exciting new ways to engage students and have them enthusiastic about doing their own scientific research and learning about new discoveries." After completing the research experience these sentiments were further reinforced longitudinally in each of the three periods where data was collected. Progressing from the end of the summer research experience to the fall workshop and finally the winter interview chosen comments corroborate Betty's feeling of instilling in her students the idea that they are scientist as evidence by comments such as: "The research was an eye-opening experience that will be applicable to my students - since we are supposed to make them act like scientists!" at the end of the research experience; to "I want my students to understand that they are scientists and sometimes accidents happen. I want them to problem solve where the accident occurred, since realizing it will make them more successful later on." in the fall; and finally within the winter interview, "So many of the kids think of themselves as not being scientists. They just don't put themselves in the scientist profile. Or scientists are people way off and high and mighty. 'I'm not a scientist myself [a student will say]', but they are. They need to realize they are." From the coded artifacts, it was clear that Betty's feelings toward her students as scientists was something she brought into the experience even though it was further reinforced upon completion and reflection of the experience.

\section{Understanding Research}

Prior to the RET program experience, Betty had not formally participated in science or engineering research. While she was familiar with the enterprise of research, the scientific 
method, and curricular content at a level commensurate with being labeled highly effective, the end definitions were of the rote variety and not experiential or working. Without an authentic research experience, Betty would not have been able to articulate some of the less glamorous elements inherent in research, the enterprise of research. Directly following the summer research experience, Betty stated, "What I am finding to be applicable to my teaching is the research as a whole. The concepts of experimental error, following procedures correctly, graphing and creating detailed tables for data, and documenting adequately are all concepts that I will be able to apply in my classroom." As time progressed into the school year allowing for adequate reflection time, the same types of themes remained in Betty's written and verbal responses. At the fall workshop, Betty reiterated her working sense of research in that it is not perfect or predictable, yet it is always happening. The working components of the scientific method also remained revealing their impact. During the winter interview, six months after the research experience Betty's perception of a more accurate understanding of how research is done remained. As evidenced by two quotes:

[1] Prior to this I would have not seen myself as being able to do research. But now, it's like "I'm actually not too bad at this". It's a matter of keeping data straight and it's not as, I don't want to say it's not difficult, but it's not as distant and out of reach as what I thought it was.

[2] My big thing that impacted me was the actual research is not nearly as picture perfect as it would like to seem to be. Its like "oh wow, you just spent two weeks doing that and it really doesn't tell us anything so do it again" Its like "I just did it". Research is not quick. I guess just getting into it and being in the trenches I can understand why we don't have a cure for cancer. It is not a fast thing. It is a trial and error process. My biggest thing is letting people experience it.

Clearly Betty has experienced a lasting change and shift in perception of research and what is involved as a result of participating in an authentic research experience.

\section{Collaboration}

There is a disconnect between the post-secondary community and the K-12 community that is evidenced by Betty's consistent referral to collaboration. In each of the three time period responses, Betty expresses her desire to collaborate in some capacity with the science and engineering community for the purpose of enhancing her students' science experience. The collaborations she hoped to foster involved scientists and engineers visiting her classroom and working with her students in some capacity, either in a demonstration/lecture format highlighting their respective field or by working more directly with students as a resident expert. The collaboration intentions were not isolated to SDSM\&T. The research experience seemingly opened Betty's eyes to the wealth of resources available and the research occurring throughout the region. It provided Betty with a sense of empowerment that these resources are available, approachable and willing to assist.

\section{Conclusions and Implications}

It is clear that the RET model of professional development has its place within the greater scheme of support structures for K-12 STEM teachers. Caution must be taken to guard against 
making the RET model more than what it is capable of being. The RET model is not the end all and be all of professional development, but it does successfully serve a niche. While the current niche the RET model of professional development serves is focused and somewhat small, there is potential to move beyond the current structure as the NSF has authored it.

As the validity of the RET model becomes standard and research scientists and engineers are mindful of the ongoing nature of pipeline issues, funding should begin to come from other sources, as well as from the NSF. For example, as research scientists and faculty within departments of science and engineering prepare proposals, a required outreach component could build in funds for an RET style of collaboration. Another example would be for funds to come directly through the university and/or adjacent K-12 school districts. The value of the RET model has ramifications for colleges of education as well. Institutions responsible for preparing future science teachers should take a hard look at making a RET model style course a requirement along with traditional student teaching responsibilities. Consistent with the aforementioned would be for colleges of education and departments of curriculum and instruction to have a RET model component as part of a science specialist endorsement or as part of a master of science in science education program. Either approach would have positive impacts on traditional preparatory efforts.

The RET model of professional development has an inherent logic which is further corroborated by the current body of literature. Teachers who have experienced this type of professional development along with those in capacities of administration can easily expound upon the benefits of such a program in relation to their circle of influence. To fully realize the potential of K-12 and university collaborations in the form of the RET model, further research needs to be conducted on student impact and a sense of urgency needs to be fostered for making the current and future science teacher workforce as prepared for the task at hand as possible. The urgency is there but finding where the RET model fits in to the grand scheme of things has yet to be realized.

\section{Future Directions}

The most pressing need for research is the development of a mechanism that will accurately gauge how a teacher's participation in RET model programs impacts student knowledge and performance in STEM content areas. As could be expected this charge quickly becomes very complex. First, it is necessary to understand how and to what extent the teacher has been impacted by the RET model program. The areas of interest, such as beliefs and efficacy towards their STEM field of teaching, present difficulties in qualifying. Once the data on teacher impact is secured the research can begin to look at student impact. The task does not get any easier because of the myriad of variables that must be considered when attempting to get at the heart of this difficult research question. Teachers often naturally evolve with experience and the dynamics in a classroom during any given school year are often dictated by the highly complex nature of the student population. The crux of the dilemma is being able to isolate those factors resulting from the RET model program experience of the teacher and making the connection with how those isolated factors impact students in a positive or negative way that is different from student achievement and knowledge gained in a classroom by a teacher that has not experienced this type of professional development. 
Other areas for future exploration would relate to teacher beliefs and efficacy changes. The literature to date is homogenous in the sense that teachers who have participated in RET model programs rave about their experiences and how positive they were. This type of literature provides multitudinous sound bytes that do have value but only to a certain extent. By beginning to quantify shifts teachers experience in their knowledge and beliefs about STEM content into established theoretical contexts, a greater level of validity would be given to the RET model of professional development. Once this is done, the RET model can be extended to consider implications for those teachers not in the upper echelon of the profession. By opening up this avenue, research could then begin to look at this model of professional development for those teachers who do not have the content background commiserate with what is considered highly effective for their field. Can the RET model provide hope to those teachers who do not have a degree within the content area in which they teach? The potential is there but contingent upon the RET model of professional development becoming solvent at universities without the reliance upon the NSF for ongoing financial support.

\section{Acknowledgments}

The authors acknowledge the support of the National Science Foundation (NSF EEC 0502310).

\section{Bibliography}

1. Rhoton, J., \& Bowers, P. (Eds.).. Issues in science education: Professional development planning and design. Arlington, VA: NSTA Press, 2001.

2. Yager, R. E. (Ed.). Exemplary science: Best practices in professional development. Arlington, VA: NSTA Press, 2005.

3. Banilower, E. R., Heck, D. J., \& Weiss, I. R. Can professional development make the vision of the standards a reality? The impact of the National Science Foundation's local systemic change through teacher enhancement initiative. Journal of Research in Science Teaching, 44(3), 375-395, 2007.

4. Ball, D. L., \& Cohen, D. K. Developing practice, developing practitioners: Toward a practice-based theory of professional education. In L. Darling-Hammond and G. Sykes (Eds.), Teaching as the learning profession (pp. 3-31). San Francisco: Jossey-Bass, 1999.

5. Koch, J. Presidents newsletter message: Janice Koch ASTE president: 50 years after Sputnik. ASTE Newsletter, 42(1), 1-2, 2007, Fall.

6. National Academies of Engineering, The engineer of 2020: Visions of Engineering in the New Century, National Academies of Engineering Press, 2005.

7. National Academy of Sciences, National Academy of Engineering, \& Institute of Medicine, Rising above the gathering storm: Energizing and employing America for a brighter economic future. Washington, DC: National Academies Press, 2006.

8. National Research Council. National science education standards. Washington, DC: National Academy Press, 1996.

9. American Association for the Advancement of Science. Science for all Americans, New York: Oxford University Press, 1990.

10. Russell, S. H., \& Hancock, M. P., Evaluation of the research experiences for teachers (ret) program: 2001-2006 (SRI Project P13392). Menlo Park, CA: SRI International, 2007, July.

11. Averett, S., Are you experienced?. Industrial Engineer, 35(9), 36-39, 2003.

12. Brown, S., \& Melear, C., Preservice teachers' research experiences in scientists' laboratories. Journal of Science Teacher Education, 18(4), 573-597, 2007. 
13. Dempsey, B., Hibbett, D., \& Binder, M., Bridging the gap between classrooms and research laboratories: One teacher's RET experience working in a mycology lab. The Science Teacher, 74(4), 33-37, 2007.

14. Dresner, M., \& Worley, E., Teacher research experiences, partnerships with scientists, and teacher networks sustaining factors from professional development. Journal of Science Teacher Education, 17, 1-14, 2006.

15. Flaccus, K., Vlieg, J., Marks, J. C., \& LeRoy, C. J., Restoring Fossil Creek: An environmental science class teams up with a local university to conduct a longitudinal study. The Science Teacher, 71(6), 36-40, 2004.

16. Garofalo, J., Lindgren, R., \& O'Neill, T., Knowledge developed by a high school teacher participating in a physics research experience. Science Education, 76(1), 43-50, 1992.

17. Johnson, M., Teacher as researcher: University programs help teachers bring modern research into the secondary classroom. The Science Teacher, 40-42, 2002, March.

18. Lockhart, A., \& Le Doux, J., A partnership for problem-based learning: Challenging students to consider openended problems involving gene therapy. The Science Teacher, 72(9), 29-33, 2005.

19. Musante, S., Summer research experiences for high school teachers. BioScience, 56(7), 569, 2006.

20. Okiishi, T., Research: Introducing teachers to the lab. Prism, 12(4), 46, 2002.

21. Ononye, G., Husting, C., Jackson, E., Srinivasan, R., Sorial, G., \& Kukreti, A., Research experience for teachers (RET): The art of formal education. Journal of Environmental Engineering, 133(1), 2-3, 2007.

22. Raphael, J., Tobias, S., \& Greenberg, R., Research experience as a component of science and mathematics teacher preparation. Journal of Science Teacher Education, 10(2), 147-158, 1999.

23. Westerlund, J. F., Garcia, D. M., Koke, J. R., Taylor, T. A., \& Mason, D. S., Summer scientific research for teachers: The experience and its effect. Journal of Science Teacher Education, 13(1), 63-83, 2002.

24. Scowcroft, G. A., \& Knowlton, C., Proceedings of the conference on teacher research experiences. Retrieved December 7, 2007, from http://omp.gso.uri.edu/ctre/ppt/CTRE_Proceedings_5-06.pdf, 2005, April 24-27.

25. Borko, H., Professional development and teacher learning: Mapping the terrain. Educational Researcher, 33(8), 3-15, 2004.

26. Wiggins, G., McTighe, J., Understanding by design, ASCD, 1998.

27. Erickson, H. L., Concept-based curriculum and instruction: Teaching beyond the facts, Corwin Press, Inc., 2002.

28. R.K. Yin, Case study research: Design and methods. Sage Publications, Thousand Oaks, CA (1994).

29. P. Darke, G. Shanks, and M. Broadbent, Successfully completing case study research: Combining rigour, relevance, and pragmatism. Information Systems Journal, 8, 273-289 (1998).

30. R.K. Yin, Case study research: Design and methods, Third edition. Sage Publications, Thousand Oaks, CA (2004).

31. Wainwright, C., Flick, L., Morrell, P. D., Schepige, A., Observation of reform teaching in undergraduate level mathematics and science courses. School Science and Mathematics, 104(7), 322-336, 2004. 